\title{
Skeletal-Specific Expression of Fgd1 During Bone Formation and Skeletal Defects in Faciogenital Dysplasia (FGDY; Aarskog Syndrome)
}

\author{
JEROME L. GORSKI, ${ }^{1,2 *}$ LOURDES ESTRADA, ${ }^{1}$ CHANGZHI HU, ${ }^{2}$ AND ZHOU LIU ${ }^{2}$ \\ ${ }^{1}$ Department of Human Genetics, University of Michigan Medical School, Ann Arbor, Michigan \\ ${ }^{2}$ Department of Pediatrics and Communicable Diseases, University of Michigan Medical School, Ann Arbor, Michigan
}

\begin{abstract}
FGD1 encodes a guanine nucleotide exchange factor (GEF) that specifically activates the Rho GTPase Cdc42; FGD1 mutations result in Faciogenital Dysplasia (FGDY, Aarskog syndrome), an $\mathrm{X}$-linked developmental disorder that adversely affects the formation of multiple skeletal structures. To further define the role of FGD1 in skeletal development, we examined its expression in developing mouse embryos and correlated this pattern with FGDY skeletal de-
\end{abstract} fects. In this study, we show that Fgd1, the mouse FGD1 ortholog, is initially expressed during the onset of ossification during embryogenesis. Fgd1 is expressed in regions of active bone formation in the trabeculae and diaphyseal cortices of developing long bones. The onset of Fgd1 expression correlates with the expression of bone sialoprotein, a protein specifically expressed in osteoblasts at the onset of matrix mineralization; an analysis of serial sections shows that Fgd1 is expressed in tissues containing calcified and mineralized extracellular matrix. Fgd1 protein is specifically expressed in cultured osteoblast and osteoblast-like cells including MC3T3-E1 cells and human osteosarcoma cells but not in other mesodermal cells; immunohistochemical studies confirm the presence of Fgd1 protein in mouse calvarial cells. Postnatally, Fgd1 is expressed more broadly in skeletal tissue with expression in the perichondrium, resting chondrocytes, and joint capsule fibroblasts. The data indicate that Fgd1 is expressed in a variety of regions of incipient and active endochondral and intramembranous ossification including the craniofacial bones, vertebrae, ribs, long bones and phalanges. The observed pattern of $\mathrm{Fgd1}$ expression correlates with FGDY skeletal manifestations and provides an embryologic basis for the prevalence of observed skeletal defects. The observation that the induction of Fgd1 expression coincides with the initiation of ossification strongly suggests that FGD1 signaling plays a role in ossification and bone formation; it also suggests that FGD1 signaling does not play a role in the earlier phases of skeletogenesis. With the observation that FGD1 mutations result in the skeletal dys- plasia FGDY, accumulated data indicate that FGD1 signaling plays a critical role in ossification and skeletal development. (C) 2000 Wiley-Liss, Inc.

Key words: osteoblast; Cdc42; Rho protein; guanine nucleotide exchange factor; signal transduction; gene expression

\section{INTRODUCTION}

FGD1 is implicated as an important participant in skeletal formation because mutations in this gene result in the disease Faciogenital Dysplasia (FGDY), or Aarskog syndrome (Pasteris et al., 1994; Gorski, 1998), an X-linked skeletal dysplasia that adversely affects a particular set of characteristic skeletal structures (OMIM 305400). Most FGD1 mutations in FGDY patients are predicted to function as null alleles; thus the X-linked recessive phenotype appears to be due to the absence of the gene product in affected males (Pasteris et al., 1994). Although minor urogenital anomalies are associated with FGDY, FGD1 mutations appear to affect the developing skeleton most severely and skeletal abnormalities dominate the clinical manifestations of the disease (Gorlin et al., 1990; Gorski, 1998). Clinical findings typically include a unique pattern of developmental skeletal abnormalities including disproportionate acromelic short stature, widely spaced eyes (hypertelorism), maxillary and mandibular hypoplasia, hypoplastic phalanges, and delayed bone maturation. A variety of other skeletal malformations are also observed including cervical spine abnormalities such as spina bifida occulta, odontoid hypoplasia, fused cervical vertebrae, segmentation anomalies and additional pairs of ribs, and abnormally formed teeth (Gorlin et al., 1990; Porteous and Goudie, 1991). The combined clinical data indicate that FGD1 mutations adversely affect a variety of skeletal elements including the

Grant sponsor: National Institutes of Health; Grant numbers: 5T32HD07505-02 and HD34446; Grant sponsor: March of DimesBirth Defects Foundation; Grant number: 1-95-0715.

*Correspondence to: Jerome L. Gorski, M.D., Division of Pediatric Genetics, Room 3570 Medical Science Research Building II, Box 0688, University of Michigan Medical School, Ann Arbor, MI 48109-0688. E-mail: jlgorski@umich.edu

Received 8 February 2000; Accepted 13 April 2000

Published online 21 June 2000 
craniofacial bones, vertebrae, ribs, long bones and phalanges, skeletal components derived from neural crest, periaxial mesoderm, and lateral mesoderm, and components formed by both endochondral and intramembranous ossification.

Microinjection and biochemical studies show that FGD1 encodes a guanine nucleotide exchange factor (GEF) that specifically activates the p21 GTPase Cdc42, a member of the Rho (Ras homology) family of GTPase proteins (Olson et al., 1996; Zheng et al., 1996). FGD1 is one of about 25 different mammalian Rho guanine nucleotide exchange factors (RhoGEFs). However, unlike most of the RhoGEFs that were identified by transformation assay, presently, FGD1 is the only disease-specific RhoGEF in which mutations result in an inherited human developmental syndrome (Cerione and Zheng, 1996; Whitehead et al., 1997). RhoGEFs activate Rho GTPases by catalyzing the exchange of bound GDP for GTP (Cerione and Zheng, 1996). RhoGEFs, and the Rho proteins they regulate, are typically expressed throughout development in a wide range of tissues (Cerione and Zheng, 1996; Whitehead et al., 1997); however, the specific role that each RhoGEF plays during mammalian development remains to be determined. Rho GTPases regulate diverse cellular processes including the organization of the actin cytoskeleton, cellular polarity, vesicular transport, cell cycle progression, and the modulation of gene expression (Van Aelst and D'Souza-Schorey, 1997). By regulating these cellular components and processes, Rho proteins (and their RhoGEF activators) regulate cell shape, motility, and differentiation, properties critical to tissue morphogenesis (Hall, 1998). Biochemical studies show that FGD1 is a specific Cdc42 activator (Olson et al., 1996; Zheng et al., 1996). By activating Cdc42, FGD1 stimulates fibroblasts to form filopodia, cytoskeletal elements involved in cellular signaling and adhesion (Olson et al., 1996). Through Cdc42, FGD1 also activates the c-Jun N-terminal kinase signaling cascade, a pathway that regulates cell growth and differentiation. Amassed data indicate that FGD1 is an activating component of the Cdc42 intracellular signaling pathway.

To gain further understanding of the function of FGD1 in skeletal formation, we studied the expression of Fgd1, the FGD1 mouse ortholog (Pasteris et al., 1995), in the developing mouse embryo. Here we demonstrate that $F g d 1$ has a unique pattern of expression; transcripts are most abundant in the ossifying skeletal components of craniofacial bones, vertebrae, ribs, long bones and phalanges, skeletal components derived from neural crest, periaxial mesoderm, and lateral mesoderm. Immunoblot studies show that the Fgd1 protein is expressed in mouse calvarial osteoblasts, the osteoblast-like cell line MC3T3-E1, and human osteosarcoma cell lines. These results show that Fgd1 has a restricted spatiotemporal pattern of expression and that its expression is limited to regions of incipient and active ossification including the craniofacial bones. The observation that the induction of Fgd1 expression coincides with the initiation of ossification strongly suggests that FGD1 signaling plays a role in ossification but not in the earlier phases of skeletogenesis. Furthermore, these results show that the pattern of Fgd1 expression directly corresponds to the abnormalities of endochondral and intramembranous bone formation observed in Faciogenital Dysplasia. Accumulated data strongly suggests that FGD1 signaling plays a critical role in skeletal formation.

\section{RESULTS \\ RNA In Situ Hybridization Analysis of Fgd1 Expression}

Northern blot and non-quantitative RT-PCR studies were previously used to examine the pattern of FGD1 expression in a limited number of adult and embryonic human tissues (Pasteris et al., 1994, 1995); however, skeletal tissues were not included in these studies. Preliminary northern blot analyses showed that Fgd1 transcripts were predominantly expressed in mouse skeletal tissue (Pasteris et al., 1995; data not shown). Thus, to further elucidate the role of FGD1 in skeletal formation, additional studies were performed to determine a more precise spatiotemporal pattern of $\mathrm{Fgd1}$ expression during mouse embryogenesis.

Consistent with prior northern blot studies, in situ hybridization studies show that Fgd1 expression is predominantly expressed in developing skeletal tissue in the mouse embryo. The earliest evidence of $F g d 1$ expression is first detected in the base of the skull and cervical vertebrae in E14.5-E15.5 embryos (Fig. 1). In these embryos, Fgd1 transcripts are detected in the cartilage primordia of the neural arches of the cervical vertebrae and the cartilage primordia of the basioccipital bone. These skeletal components are known to contain the earliest centers of ossification; these ossification centers typically begin to form at about E14E14.5 (Kaufman, 1992). An analysis of adjacent tissue sections shows that, in the neural arches of the E14.5 cervical vertebrae and the cartilage primordia of the E15.5 basioccipital bone, the distribution of detected Fgd1 transcripts directly corresponds to regions of calcified tissue detected by alizarin $\mathrm{S}$ red stain within these skeletal elements (Fig. 1). Anti-bone sialoprotein antibodies were used to perform immunocytochemical studies on adjacent tissue sections to confirm these observations. In contrast to other bone matrix proteins, bone sialoprotein (BSP) has a very restricted tissue distribution and is almost exclusively expressed by osteoblasts at the onset of matrix mineralization (Bianco et al., 1991; Robey, 1996). An analysis of adjacent tissue sections shows that $F g d 1$ expression directly corresponds to regions of BSP protein expression in embryonic neural arch and basioccipital tissue (Fig. 1), tissues that are initiating early ossification.

Beginning at E15.5-E16.5, Fgd1 is expressed in the midshaft cortex and developing trabeculae of the developing long bones (Fig. 2). In older mouse embryos 
(E18.5) and newborn mouse pups (P1), Fgd1is expressed in the diaphysis of the long bones and within trabecular bone, regions of active bone formation. Serial tissue sections were analyzed with alizarin $\mathrm{S}$ red and Von Kossa stain to identify calcified and mineralized tissues, respectively. These studies showed that Fgd1 expression corresponds to regions of calcified and mineralized cortical and trabecular bone tissue (Fig. 2). In these embryos and pups, Fgd1 expression is limited to tissues undergoing bone formation; Fgd1 expression is not detected in non-skeletal tissue, nor is Fgd1 expressed in non-ossified skeletal tissue such as proliferating and hypertrophied chondrocytes (Fig. 2). Fgd1 expression is also observed in other skeletal elements undergoing ossification, including the ribs and the distal and proximal long bones of the upper and lower extremities (data not shown). In some tissue sections, silver grains were deposited above cornified epithelia (i.e., Figs. 2 and 3); however, control hybridizations, including the use of sense Fgd1 probe, showed that these signals were non-specific and artifactual (data not shown). With the results of the embryonic skull base and cervical vertebrae expression studies, the data show that $F g d 1$ is predominantly expressed in regions of active embryonic ossification.

An analysis of multiple E10.5-E14.5 embryos failed to identify $F g d 1$ transcripts before E14.5 (data not shown). Specifically, Fgd1 transcripts were not detected in skeletal condensations prior to E14.5, before the onset of ossification. In addition, an analysis of multiple E10.5-E14.5 embryos also failed to detect Fgd1 transcripts in non-skeletal tissue. In particular, no evidence of $F g d 1$ expression was found in the developing urogenital structures including the developing genital tubercle, a structure formed during this period of embryogenesis (Kaufman, 1992). It has been postulated that the genital tubercle may be involved in the development of FGDY urogenital anomalies (Gorlin et al., 1990). The observation that the initiation of $F g d 1$ expression coincides with the onset of ossification strongly suggests that $\mathrm{Fgd} 1$ signaling plays a role in ossification and bone formation. This observation also suggests that $F g d 1$ does not play a prominent role in the earlier phases of skeletogenesis.

Additional in situ hybridization studies were performed to determine the pattern of $F g d 1$ expression in embryonic craniofacial bones. Coronal, transverse, and sagittal sections of E18.5 embryos showed that Fgd1 was expressed in the cortex and trabeculae of the developing maxilla and mandible, the hard palate, and the inferomedial part of nasal septum (Figs. 3 and 4). These studies showed that $F g d 1$ was expressed in all of the craniofacial skeletal components containing ossification centers including the frontal, parietal, temporal, and exoccipital bones (data not shown). Fgd1 was also expressed in craniofacial cartilage primordia prior to evident ossification center formation (i.e., Fgd1 expression in the cartilage primordia of the nasal turbinate; Fig. 4E and F). In contrast, Fgd1 expression was nota- bly absent in Meckel's cartilage (Fig. 3). Detectable Fgd1 expression was also absent in the cartilage of the ear, thyroid, and trachea (data not shown), cartilaginous components that normally do not ossify. Fgd1 expression was also detected in tissues surrounding the primordia of the upper and lower incisor teeth (Figs. 3B and 4D); however, it was not possible to unequivocally identify the expressing cells. Thus, together with the results showing the pattern of Fgd1 expression in embryonic long bones and cervical vertebrae, the amassed data indicate that Fgd1 is expressed in regions of incipient and/or active endochondral and intramembranous ossification in the mouse embryo during skeletal formation.

\section{Immunoblot and Immunocytochemical Analysis of Fgd1 Expression}

Immunoblot analyses were performed to confirm that $F g d 1$ protein was expressed in primary mouse skeletal and osteoblast-like cells (Fig. 5A). When the myc epitope-tagged Fgd1 expression construct, pTGEmyc-Fgd1, was expressed in HEK 293 cells, anti-Fgd1 antibodies detected a single protein migrating at 149 $\mathrm{kDa}$. The myc-epitope monoclonal antibody (9E10) detected an identically sized protein; similar results were obtained when pTGE-myc-Fgd1 was expressed in COS1 cells (data not shown). No Fgd1 antigen was detected in non-transfected cells. As shown in Figure $5 \mathrm{~A}$, the anti-Fgd1 antibody detected a protein migrating at $107 \mathrm{kDa}$ in isolated primary mouse calvarial cells (PMC cells), a standard preparation for osteoblast cells (Majeska, 1996). The $107 \mathrm{kDa}$ size of the detected protein coincided with the predicted size of the Fgd1 protein (Pasteris et al., 1995). Anti-Fgd1 antibody detected an identically sized $107 \mathrm{kDa}$ protein in MC3T3-E1 cells, a permanent non-transformed osteoblast-like cell line derived from normal mouse bone that retains the ability to form well-developed bone matrix in culture (Sudo et al., 1983). In contrast, Fgd1 antigen was not detected in C3H10T1/2 and NIH 3T3, two independently derived permanent mouse embryonic fibroblast cell lines. Similarly, no Fgd1 antigen was detected in the non-skeletal tissues from juvenile mice including brain, skin, eye, lung, and spleen (data not shown). Fgd1 antigen was detected in two different human osteosarcoma cell lines, MG63 and SaOS2 (Fig. $5 \mathrm{~A})$. In addition to the detected 107-kDa protein, MG63 and SaOS2 homogenates contained additional crossreacting proteins; these consisted of an apparent 107 $\mathrm{kDa}$ doublet in SaOS2 cells, and 149 and $83 \mathrm{kDa}$ proteins in MG63 and SaOS2 cells, respectively. The 149 $\mathrm{kDa}$ protein detected in the MG63 cells coincided with the recombinant $F g d 1$ protein expressed in transfected HEK 293 and COS1 cells (Fig. 5A). These results show that Fgd1 protein is expressed in primary mouse calvarial cells and several different types of clonal osteoblast-like cells. Although we cannot exclude the possibility that the anti-Fgd1 antibodies may detect nonFgd1 cross-reacting proteins, the data suggest that, in 

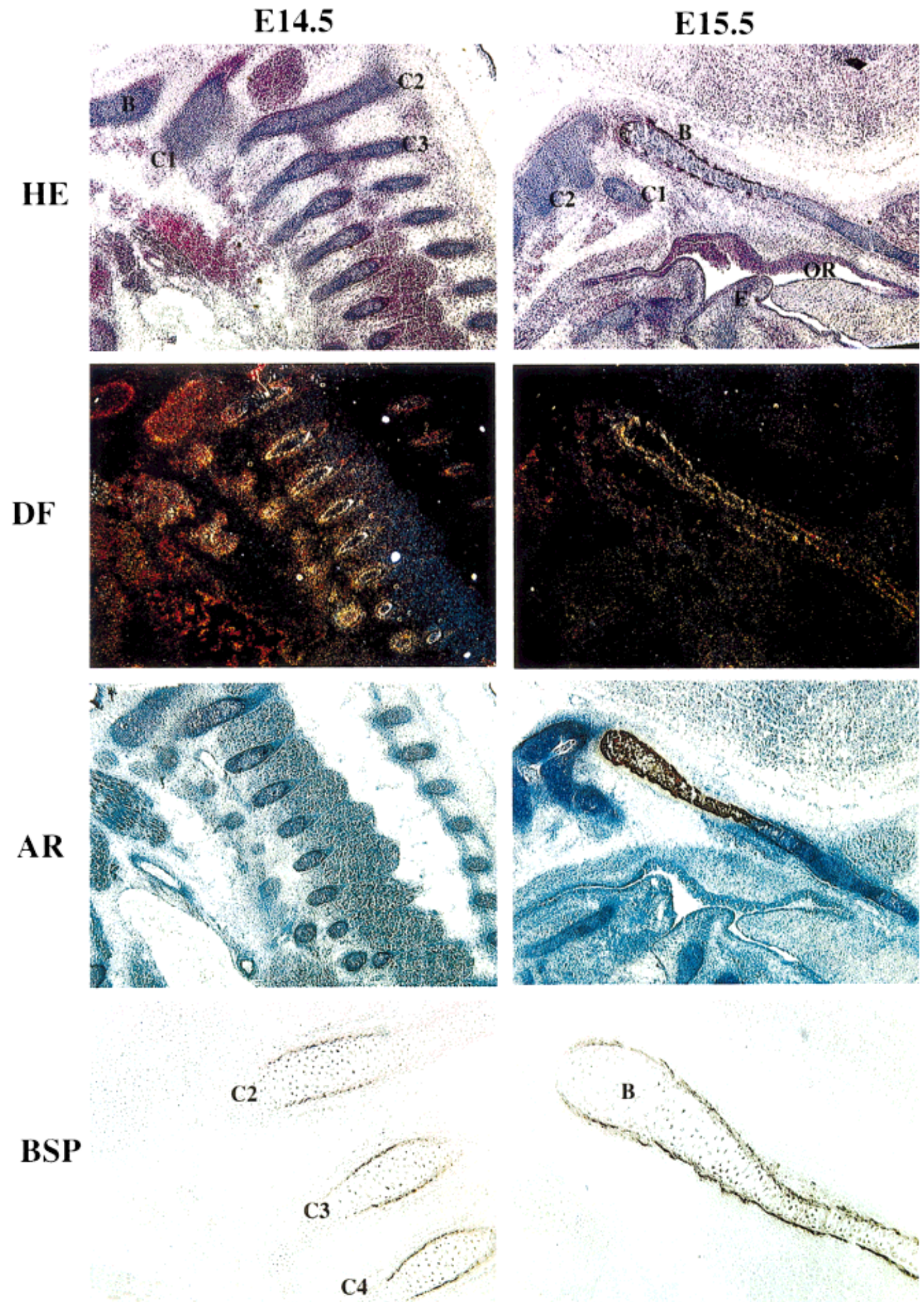

Fig. 1. Fgd1 expression in the base of the skull and cervical vertebrae. Serial sagittal sections of the head and neck of E14.5 and E15.5 mouse embryos were used for in situ hybridization. Successive sections were used to visualize the spatiotemporal pattern of Fgd1 expression (dark field, DF) compared to the morphology of adjacent tissue sections stained with hematoxylin and eosin ( $\mathrm{HE})$, alizarin $\mathrm{S}$ red (AR), and immunohistochemical staining with bone sialoprotein antibody (BSP): B, cartilage primordium of the basioccipital bone (clivus); C, cartilage primor- dium of the body and neural arch of a cervical vertebra ( $\mathrm{C} 1$, the first vertebra; C2, the second vertebra, etc.); E, epiglottis; OR, oropharynx. Precipitated silver grains indicative of detected Fgd1 transcript appear white against black under dark field illumination. Calcified tissue stains reddish brown with alizarin red and bound BSP antibody and attached $\mathrm{DAB} /$ metal reagent stain black. Photomicrographs showing BSP immunohistochemical staining are shown at higher magnification. 

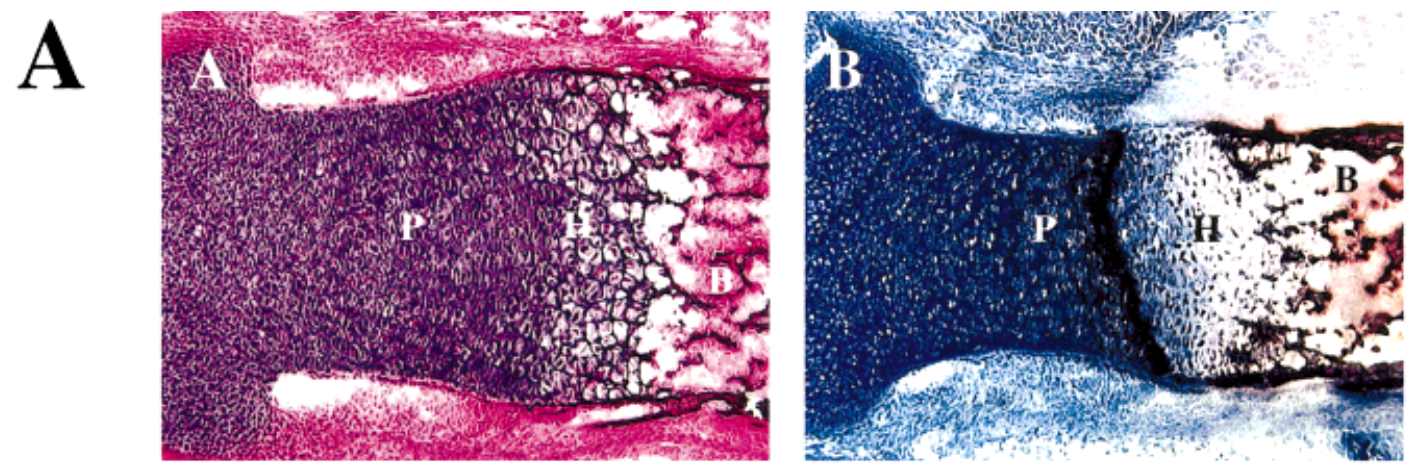

\section{B}
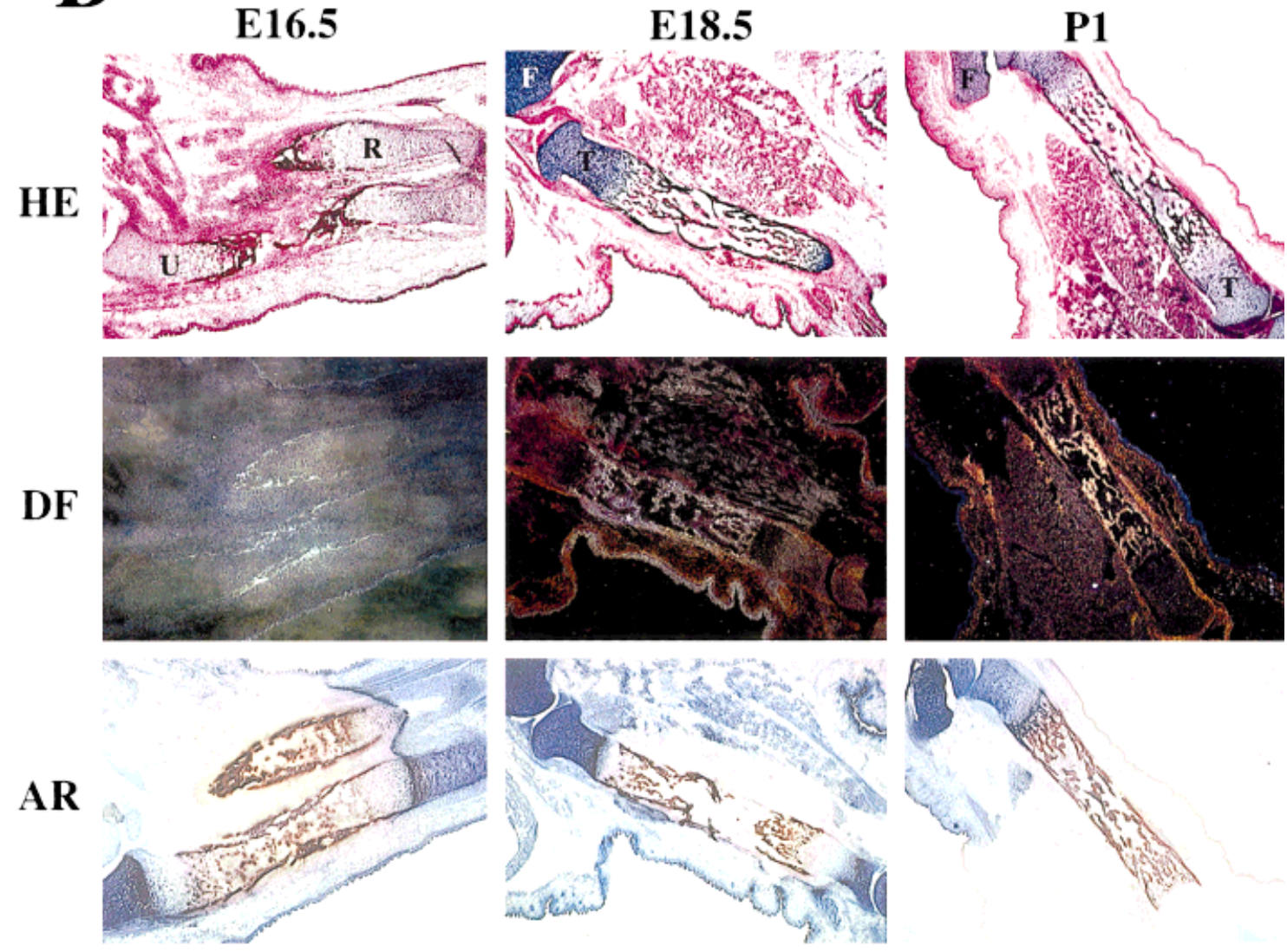

VK

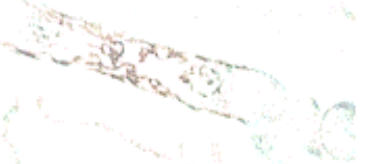

Fig. 2. Expression of Fgd1 in the cortex and trabeculae of developing long bones. A: Morphology of a growth plate and diaphysis of a tibia at high-power magnification. Longitudinal sections of a tibia from an E18.5 mouse embryo were stained with hematoxylin and eosin $(A)$ to visualize the morphology of the growth plate and the bony trabeculae of the diaphysis and alizarin red $(B)$ to differentiate between cartilage (dark blue) and bone (reddish brown): $\mathrm{P}$, proliferating chondrocytes; $\mathrm{H}$, hypertrophic chondrocytes; B, bony trabeculae and bone marrow. B: Fgd1 expression in mouse long bones. Serial longitudinal sections of the long bones of E16.5 and E18.5 mouse embryos and 1-day-old mouse pups (P1) were used for isotopic in situ hybridization; longitudinal sections of the radius and ulna (E16.5) and the tibia (E18.5 and $\mathrm{P} 1)$ are shown. Serial sections were used to visualize the spatiotemporal pattern of Fgd1 expression (dark field, DF) compared to the morphology of adjacent tissue sections stained with hematoxylin and eosin (HE), alizarin red (AR), and Von Kossa stain (VK); R, radius; U, ulna; T, tibia; F, femur. Mineralized tissue stains black with Von Kossa reagent. 

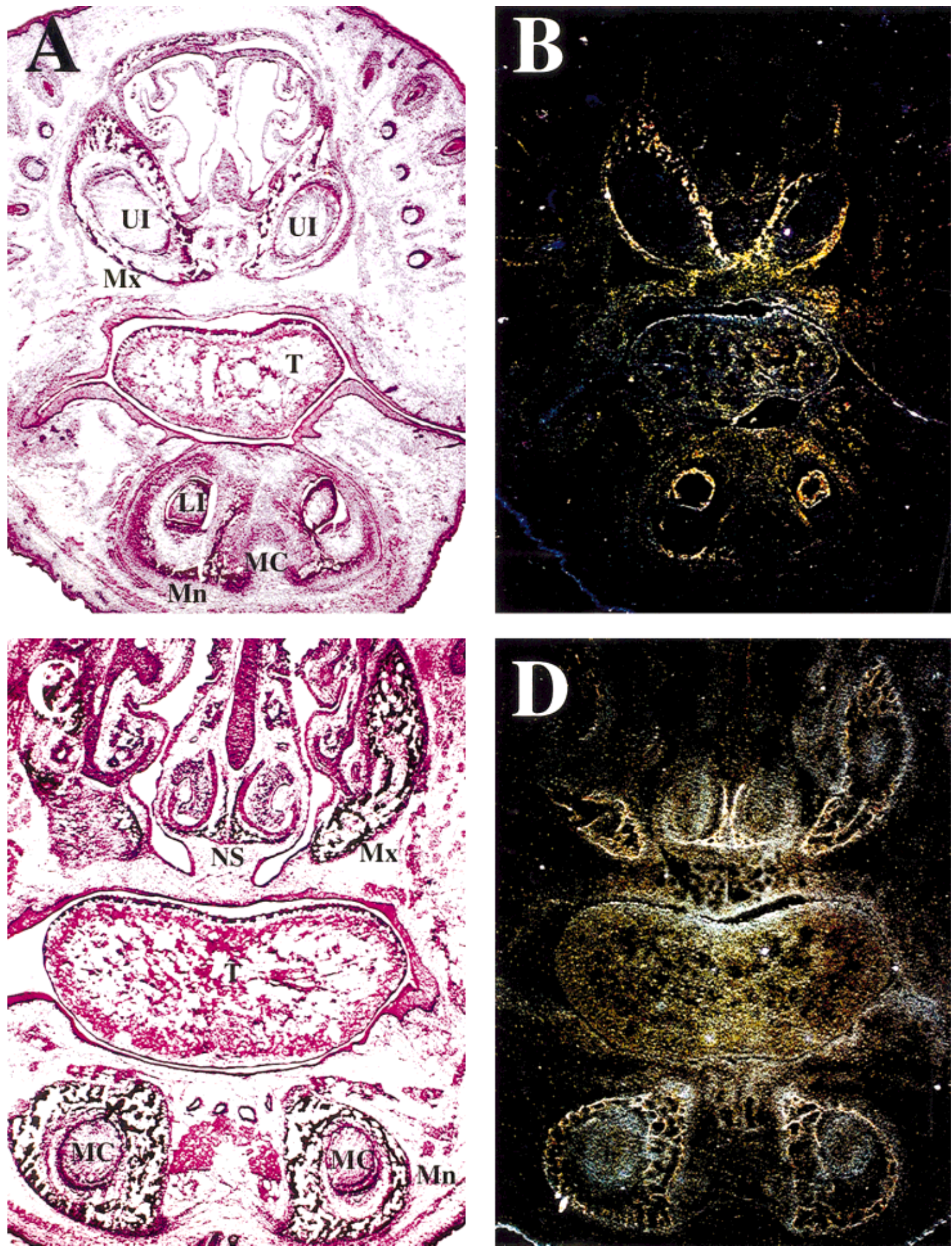

Fig. 3. Fgd1 expression in embryonic craniofacial bones (part 1). Coronal sections of the head of an E18.5 mouse embryo were used for in situ hybridization. Serial sections stained with hematoxylin and eosin (HE) show the anterior $(\mathbf{A})$ and mid-segment parts of the mandible and maxilla (C). Dark field sections immediately adjacent to the HE sections

show the pattern of Fgd1 expression in these tissues (B,D); LI, primordium of the lower incisor; MC, Meckel's cartilage; Mn, mandible; Mx, maxilla; NS, ossification in inferomedial part of nasal septum; T, tongue; $\mathrm{UI}$, primordium of the upper incisor. 

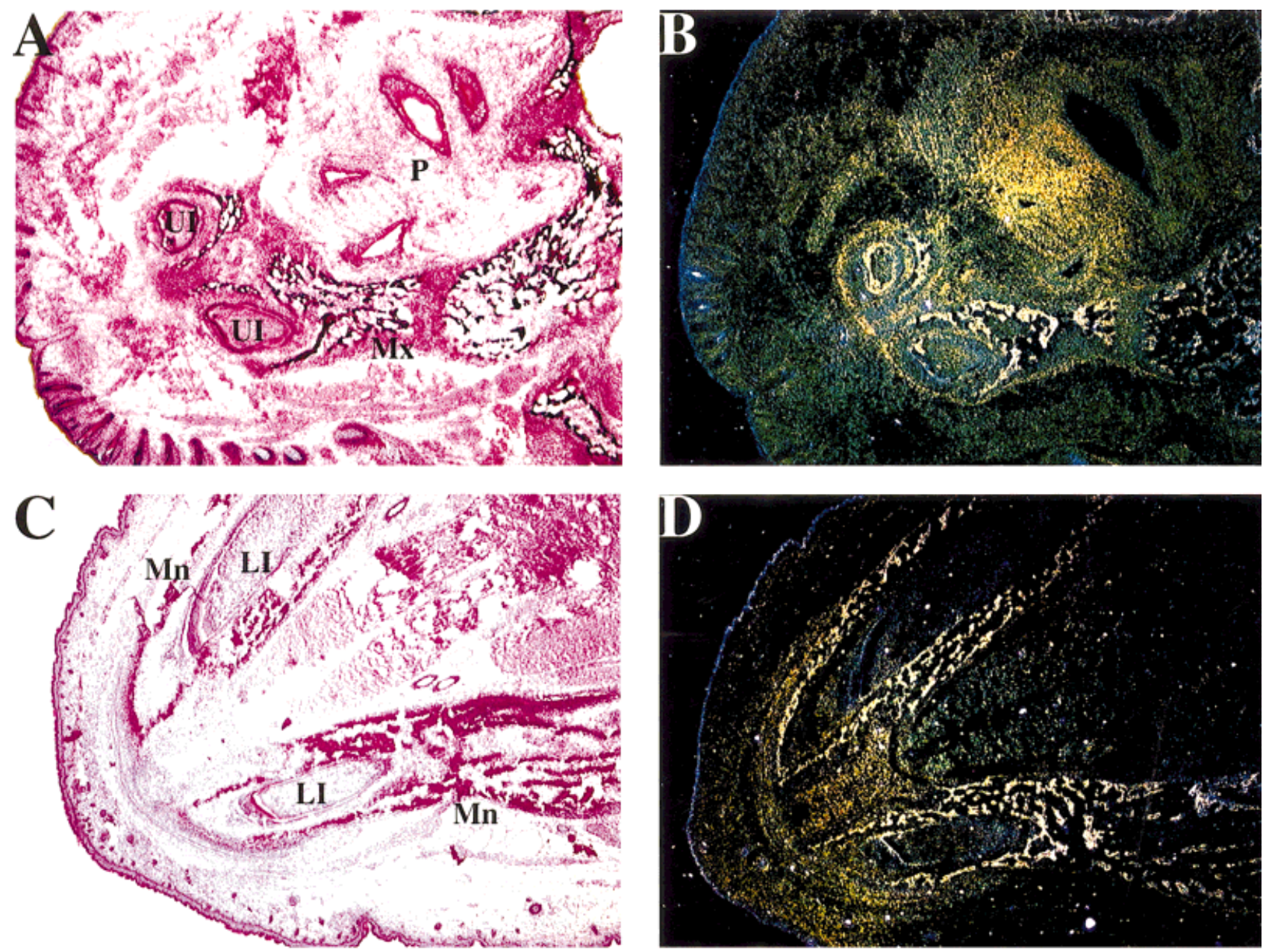

$\mathbf{E}$

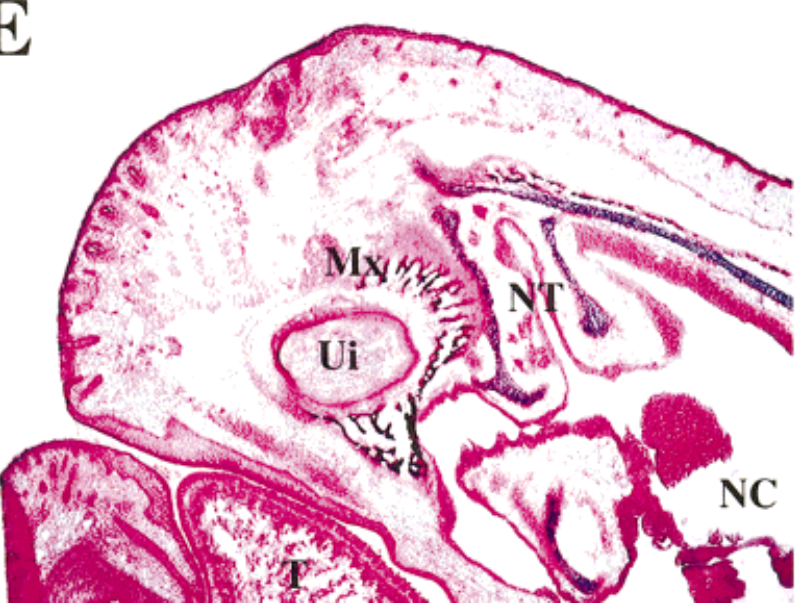

Fig. 4. Fgd1 expression in embryonic craniofacial bones (part 2). Transverse $(\mathbf{A}-\mathbf{D})$ and sagittal $(\mathbf{E}, \mathbf{F})$ sections of the head of an E18.5 mouse embryo were used for in situ hybridization. Serial sections stained with hematoxylin and eosin (HE) show two transverse sections through the palate $(A)$ and mandible $(C)$, respectively, and a sagittal section through the anterior part of the head (E). Dark field sections immediately

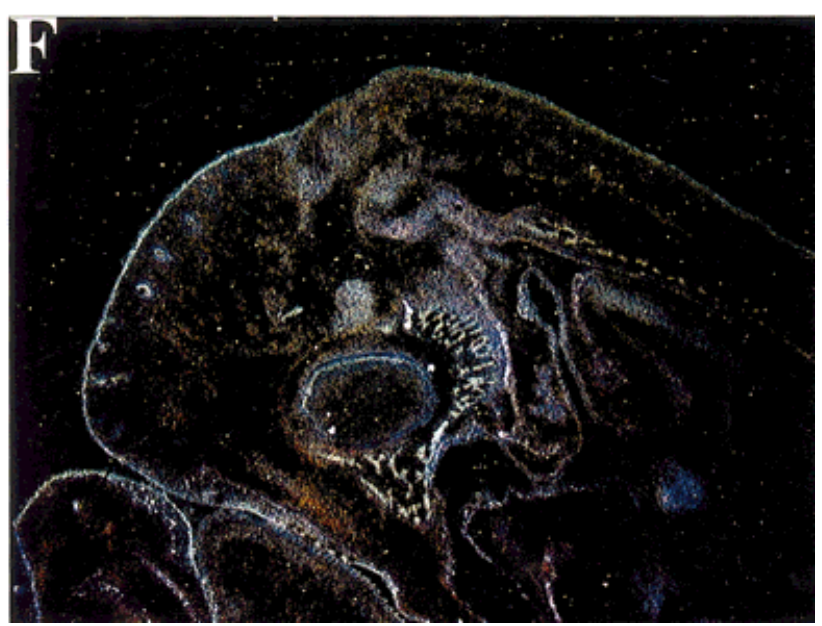

adjacent to the HE sections show the spatiotemporal pattern of Fgd1 expression in these tissues (B, D, and F); LI, lower incisor primordium; $\mathrm{Mn}$, mandible; Mx, maxilla; NC, nasal cavity; NT, cartilage primordium of the nasal turbinate; $\mathrm{P}$, palate shelf; $\mathrm{T}$, tongue; $\mathrm{UI}$, upper incisor primordium. 
A

209 kDa -

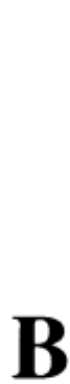

80
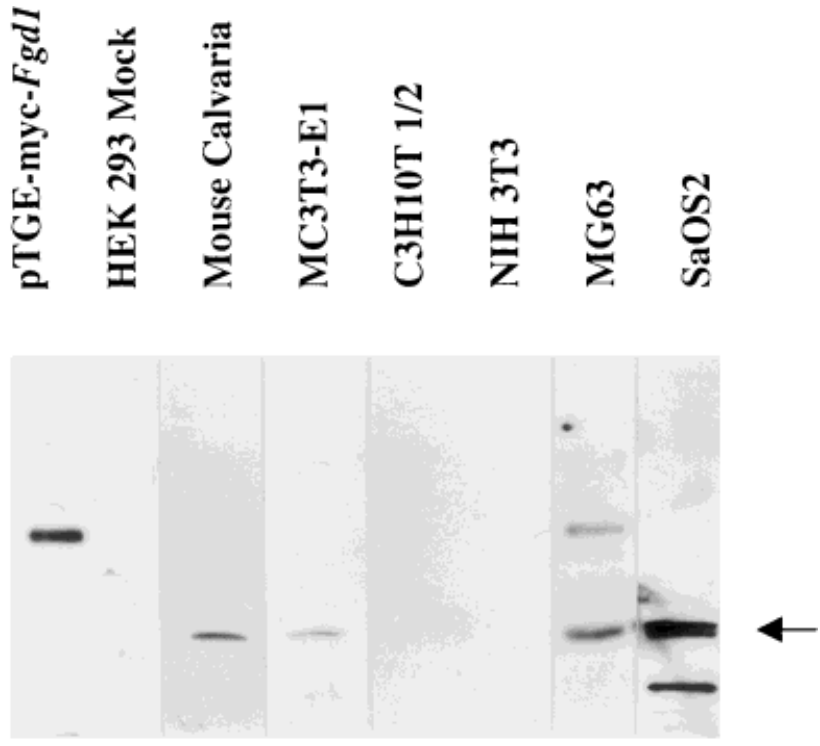

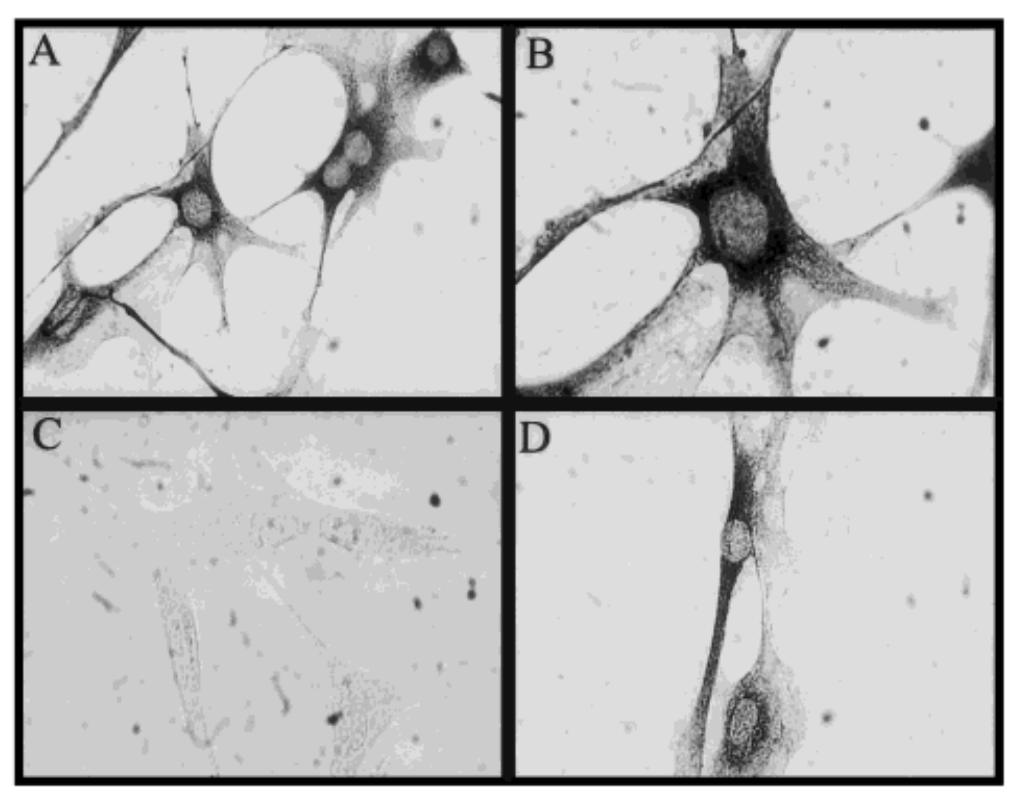

Fig. 5. Fgd1 protein is expressed in primary mouse calvarial and osteoblast-like cells. A: Cellular homogenates were studied by immunoblot analysis to identify cells expressing Fgd1 protein. Homogenates were obtained from human embryonic kidney 293 cells (lane 2; $200 \mu \mathrm{g}$ protein), 293 cells transfected with the Fgd1 expression construct pTGEmyc-Fgd1 (lane 1; $10 \mu \mathrm{g}$ protein), primary mouse calvarial cells (PMC cells) (lane $3 ; 50 \mu \mathrm{g}$ protein), mouse osteoblast-like MC3T3-E1 cells (lane $4 ; 100 \mu \mathrm{g}$ protein), permanent mouse fibroblast cells C3H10T1/2 (lane $5 ; 200 \mu \mathrm{g}$ protein) and NIH3T3 (lane $6 ; 200 \mu \mathrm{g}$ protein), and human

some cells, $\mathrm{Fgd1}$ protein may be post-translationally modified. Previous studies identified several potential N-linked glycosylation sites in the predicted Fgd1 sequence (Pasteris et al., 1994); the specific nature of osteosarcoma cells MG63 (lane 7; $200 \mu \mathrm{g}$ protein) and SaOS2 (lane 8; $100 \mu \mathrm{g}$ protein). The epitope-tagged recombinant Fgd1 protein migrates at an estimated $149 \mathrm{kDa}$. A protein migrating at $107 \mathrm{kDa}$ (arrow), the predicted size of the Fgd1 protein, is detected by the anti-Fgd1 antibody. B: Immunohistochemical analysis of $F g d 1$ protein expression in PMC cells. PMC cells stain with the anti-Fgd1 antibody (A, low-power magnification; $B$, high-power magnification). No background staining is detected in PMC cells stained with rabbit pre-immune serum (C). PMC cells stain with anti-bone sialoprotein (BSP) antibody (D).

Fgd1 post-translational modification remains to be determined.

Immunohistochemical staining was performed with anti-Fgd1 antibodies to confirm the expression 

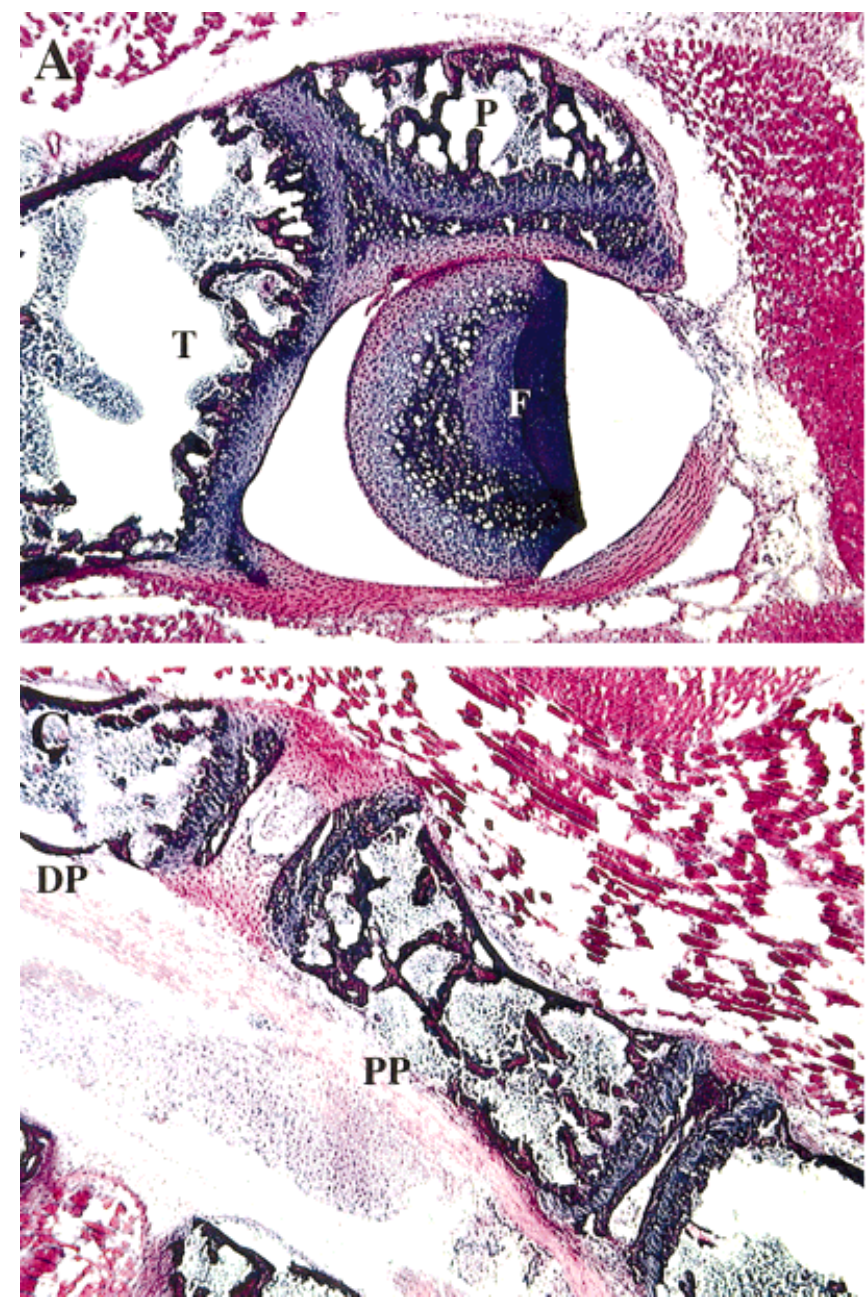

Fig. 6. Fgd1 expression in the skeletal tissues of a juvenile mouse. Serial longitudinal sections of the long bones of a 14-day-old juvenile mouse were used for in situ hybridization. Sections stained with hematoxylin and eosin (HE) show the proximal tibia (A) and the proximal and
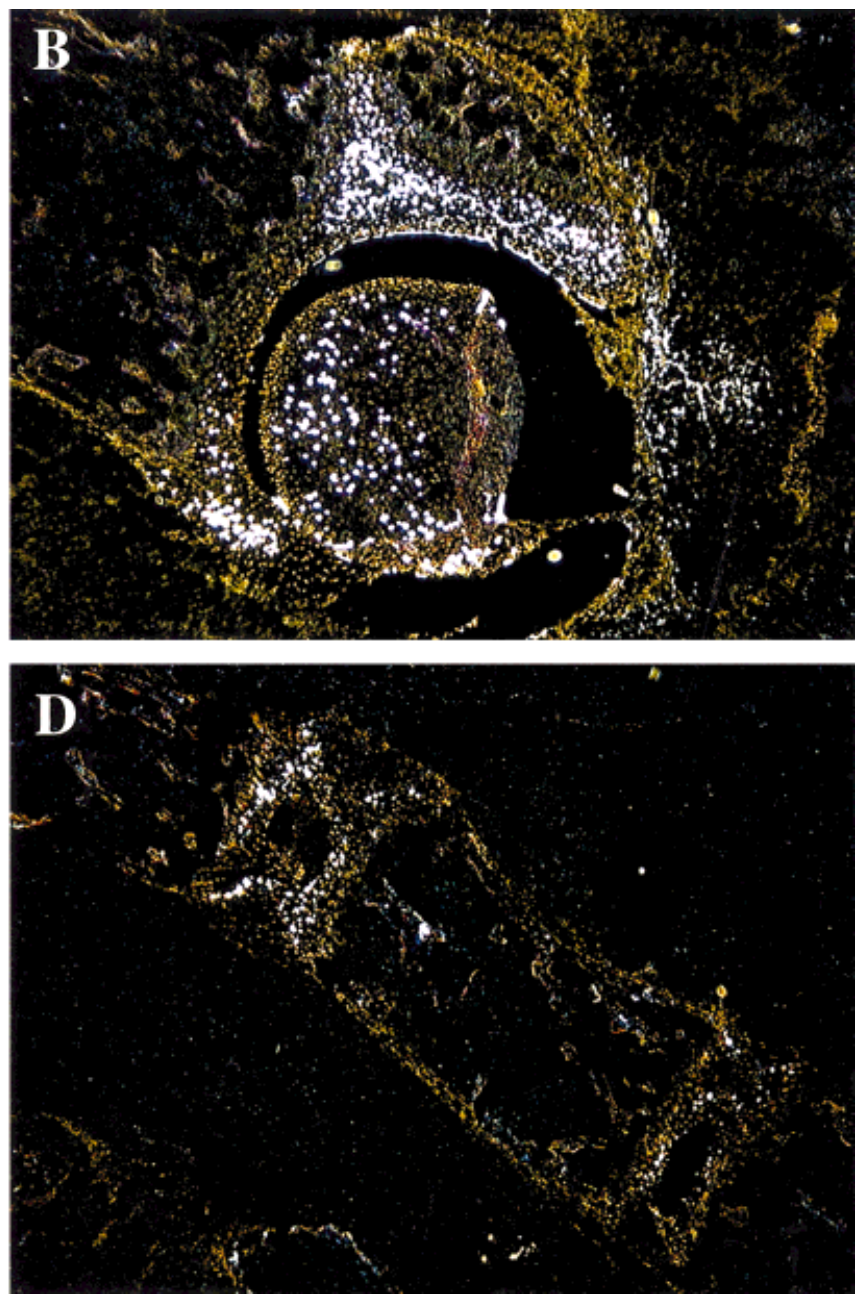

distal phalanges of the upper extremity $(\mathbf{C})$. Dark field sections immediately adjacent to the HE sections show the spatiotemporal pattern of Fgd1 expression in these tissues (B,D); DP, distal phalanx; F, femur; P, patella; PP, proximal phalanx; T, tibia. of Fgd1 protein expression in PMC cells (Fig. 5B). When studying PMC cell fractions most competent in forming mineralized bone tissue as assayed by cultured bone nodule formation (see Cell Lines and Primary Mouse Cells; fractions 3 and 4 ), $>90 \%$ of the cells examined stained with anti-Fgd1 antibody. A similar proportion of cells stained with the anti-BSP antibody. In contrast, no background staining was detected with pre-immune sera (Fig. 5B). These studies show that $F g d 1$ protein is expressed in primary osteoblasts and clonal pre-osteoblast cell lines, data consistent with the RNA in situ hybridization studies. Although we can not exclude the possibility that Fgd1 protein may be expressed in additional cells during skeletogenesis, together these results indicate that $\mathrm{Fgd1}$ is expressed in osteoblasts and preosteoblasts during endochondral and intramembranous bone formation in the mouse embryo.

\section{Fgd1 Expression in the Skeletal Components of} 2-Week-Old Mouse Pups

Additional in situ hybridization studies were performed to determine the pattern of Fgd1 expression in juvenile 2-week-old mice. These studies showed that, as in the mouse embryo, Fgd1 had a limited pattern of expression and that its expression was essentially confined to skeletal tissue. However, in contrast to the pattern of Fgd1 expression in embryos and newborn mouse pups, in 2-week-old mice, Fgd1 was predominantly expressed in the perichondrium, resting chondrocytes, and joint capsule fibroblasts within the joints of the upper and lower extremities (Fig. 6). This pattern of expression was observed in both the proximal (knee) and distal (interphalangeal) joints. Although a small amount of Fgd1 expression was detected in the bony trabeculae of the long bones, Fgd1 expression 
TABLE 1. Skeletal Features in Faciogenital Dysplasia Patients ${ }^{\text {a }}$

\begin{tabular}{lccr}
\hline Skeletal abnormality & Published cases & Michigan series & Total frequency (\%) \\
\hline Short stature (<3rd centile) & $86 / 98$ & $15 / 16$ & $101 / 114(89)$ \\
Delayed ossification centers & $\mathrm{NA}$ & $14 / 16$ & $14 / 16(88)$ \\
Hypertelorism & $89 / 100$ & $16 / 16$ & $105 / 116(91)$ \\
Maxillary hypoplasia & $84 / 104$ & $14 / 16$ & $89 / 120(74)$ \\
Broad nasal bridge & $50 / 75$ & $13 / 16$ & $63 / 91(69)$ \\
Cervical spine anomalies & $\mathrm{NA}$ & $9 / 16$ & $9 / 16(56)$ \\
Rib and sternal anomalies & $34 / 74$ & $5 / 16$ & $39 / 90(43)$ \\
Short/broad hands & $63 / 77$ & $15 / 16$ & $78 / 93(84)$ \\
Brachydactyly & $63 / 77$ & $14 / 16$ & $77 / 93(83)$ \\
Hypoplastic phalanges & $37 / 45$ & $10 / 16$ & $47 / 61(77)$ \\
Syndactyly & $45 / 73$ & $13 / 16$ & $58 / 89(65)$ \\
Joint laxity & $46 / 64$ & $12 / 16$ & $58 / 80(72)$ \\
\hline
\end{tabular}

${ }^{a} \mathrm{NA}$ denotes that information is not available in the literature.

were predominantly limited to the perichondrium, resting chondrocytes, and joint capsule fibroblasts. Fgd1 expression was not detected in non-skeletal tissue. These results indicate that, while $F g d 1$ expression may be limited to osteoblasts and pre-osteoblasts during mouse embryogenesis, postnatally, Fgd1 exhibits a broader pattern of expression. Therefore, in addition to the role it plays in osteoblast biology, Fgd1 may play a broader role in mammalian skeletogenesis.

\section{Skeletal Abnormalities Observed in Faciogenital Dysplasia}

To provide a correlation between the spatiotemporal pattern of Fgd1 expression and skeletal anomalies, we reviewed the spectrum of skeletal abnormalities reported in the literature and evaluated by us in more than 110 patients with Faciogenital Dysplasia (Gorlin et al., 1990; Porteous and Goudie, 1991). All patients had multiple skeletal abnormalities; the frequency of each of the skeletal abnormalities was tabulated and summarized in Table 1. As previously recognized, craniofacial anomalies (hypertelorism, maxillary hypoplasia, and a broad nasal bridge), short stature, and anomalies of the distal extremities (brachydactyly and hypoplastic phalanges) were prevalent among FGDY patients. While not tabulated in the literature, delays in the appearance of ossification centers and cervical spine anomalies were commonly observed among our series of patients. The skeletal components adversely affected by the FGDY phenotype are diverse and include the craniofacial bones, vertebrae, ribs, long bones and phalanges, skeletal components derived from neural crest, periaxial mesoderm, and lateral mesoderm and components formed by both endochondral and intramembranous ossification. These skeletal abnormalities coincide with regions that predominantly express murine Fgd1.

\section{DISCUSSION}

In this study, we demonstrate that Fgd1 is expressed in a unique and limited spatiotemporal pattern that is restricted to developing skeletal elements. Fgd1 is ini- tially expressed during embryogenesis within the cartilage primordia of the cervical vertebrae and basioccipital bone and this expression coincides with the onset of ossification. Later in embryogenesis, $F g d 1$ is expressed in regions of active bone formation in the trabeculae and diaphyseal cortices of developing long bones. Fgd1 is also expressed in the cartilage primordia and ossified components of embryonic craniofacial bones. Immunoblot analyses show that $F g d 1$ protein is expressed in human osteosarcoma cells and cultured osteoblast and osteoblast-like cells including primary mouse calvarial and clonal MC3T3-E1 cells, cells that form bone nodules in culture. Postnatally, Fgd1 is expressed more broadly in skeletal tissue with expression in the perichondrium, resting chondrocytes, and joint capsule fibroblasts. The data indicate that, during mouse skeletogenesis, $\mathrm{Fgd} 1$ is expressed in a variety of regions of incipient and/or active endochondral and intramembranous ossification including the skull and craniofacial bones, vertebrae, ribs, long bones and phalanges, skeletal components derived from neural crest, periaxial mesoderm, and lateral mesoderm. The observed pattern of Fgd1 expression correlates with the skeletal manifestations resulting from human FGD1 mutations in Faciogenital Dysplasia. We conclude that the characteristic skeletal abnormalities of FGDY are the direct result of deficiencies in FGD1 signaling. The data indicate a unique and critical role for FGD1 signaling in osteoblast and skeletal development.

The data show that, during mouse embryogenesis, the induction of Fgd1 expression coincides with the initiation of ossification. These results strongly suggest that Fgd1 signaling plays a role in ossification and bone formation, a finding supported by the observation that FGD1 mutations result in the skeletal dysplasia FGDY. These results also suggest that $F g d 1$ signaling does not play as significant a role in the earlier phases of skeletogenesis. Skeletal formation is emerging as a complex process that requires the regulated differentiation of a variety of cell types. During embryogenesis, skeletal formation is initiated by the aggregation of undifferentiated mesenchymal cells into condensa- 
tions; these cells subsequently differentiate to form cartilaginous primordia (Eriebacher et al., 1995). During the process of endochondral ossification, portions of the cartilaginous primordia cease proliferation, become hypertrophic, and alter the extracellular matrix to allow vascularization and the replacement of cartilage with bone. Thus, the observation that Fgd1 is predominantly expressed during endochondral and intramembranous bone formation indicates that, unlike skeletal dysplasia genes that act during the formation of skeletal condensations, such as short ear and brachypodism (King et al., 1994; Storm et al., 1994), Fgd1 plays a role in embryologic ossification.

Our data indicate that Fgd1 expression demonstrates a strong correlation with structural and skeletal abnormalities comprising the Faciogenital Dysplasia phenotype. The craniofacial abnormalities observed in FGDY (maxillary hypoplasia and hypertelorism; Table 1) correspond with the observed expression pattern of Fgd1 in the developing skull bones of the mouse embryo. The cervical vertebral, rib, and sternal abnormalities directly correspond to the expression of $\mathrm{Fgd1}$ in the cartilaginous primordia of these developing skeletal elements. Fgd1 is predominantly expressed in the trabeculae and diaphyseal cortices of developing long bones of the appendicular skeleton; this expression pattern corresponds to the acromelic shortening of the long bones of FGDY patients and may, in part, explain the short stature observed in FGDY. No evidence of Fgd1 expression was found in the developing urogenital structures including the developing genital tubercle, a structure that may be affected by the observed FGDY urogenital anomalies (Gorlin et al., 1990). Thus, our data do not provide additional insight into the molecular basis for observed minor FGDY urogenital anomalies. It is possible that our analysis was not sufficiently sensitive to detect Fgd1 transcripts in these tissues. Alternatively, the spatiotemporal pattern of murine $F g d 1$ expression may differ from that observed during human embryogenesis. The generation of an Fgd1-deficient mouse mutation will assist in the further delineation of the molecular basis for the mouse and human FGDY phenotype. In postnatal mice, Fgd1 is also expressed in the perichondrium, resting chondrocytes, and joint capsule fibroblasts of the proximal and distal appendicular skeleton; this expression pattern may have significance for the joint anomalies (joint contractures and joint laxity) observed in the majority of FGDY patients (Gorlin et al., 1990; Porteous and Goudie, 1991). In addition, the RNA in situ hybridization and immunoblot studies show that Fgd1 expression coincides with incipient and active ossification; this expression pattern corresponds to the generalized delay of ossification observed in FGDY patients.

The combined data show that $F g d 1$ is expressed in essentially all regions of active endochondral and intramembranous ossification. However, although the FGDY phenotype consists of some features that may cor- respond to bone formation in general (i.e., delayed ossification), FGD1 mutations typically affect the size and shape of a limited number of characteristic skeletal elements and not others. There may be several reasons as to why FGD1 mutations fail to yield a more uniform or generalized pattern of skeletal abnormalities. Although FGD1's role in the activation of Cdc42 is established (Olson et al., 1996; Zheng et al., 1996), in skeletal tissue, FGD1 may be only one of several Cdc42 activators. Multiple mammalian RhoGEF proteins have been shown to activate Cdc42, and several Cdc42GEFs are known to be expressed in skeletal tissue (Whitehead et al., 1997). Thus, the observed FGDY phenotype is likely to be the result of only a partial deficiency in Cdc42 activation and, in an affected FGDY individual, different skeletal elements may display varying degrees of deficiency. While our studies demonstrate the pattern of $F g d 1$ expression, this data does not provide a measure of Fgd1 protein activity or Cdc42 signaling. Thus, the concentration of activated Fgd1 protein and/or the significance of FGD1 signaling may vary among the skeletal elements. In $S$. cerevisiae, S. pombe, D. melanogaster, and C. elegans, the loss of RhoGEF activity is functionally equivalent to the loss of the target Rho protein (Boguski and McCormick, 1993); thus, it is likely that a loss of FGD1 activity results in disrupted Cdc42 signaling. Several observations indicate that Cdc42 signaling and actin cytoskeletal regulation may play a critical role in the molecular and cellular biology of bone tissue. In embryonic chick osteoblasts, an intact actin cytoskeleton is required for the regulated expression of osteopontin in response to mechanical strains (Toma et al., 1997). Studies show that the actin cytoskeleton and the Rho signaling cascade are involved in the detection and response to fluid shear induced mechanical signaling in MC3T3-E1 osteoblasts (Pavalko et al., 1998). Additional studies have demonstrated that the actin cytoskeleton is critical for determining and maintaining osteocyte shape (Tanaka-Kamioka et al., 1998). These observations suggest that FGD1/Cdc42 signaling may play a role in the organization of the osteoblast actin cytoskeleton or in sensing mechanical stress. Although we cannot rule out the formal possibility the FGD1 may be involved in additional signaling pathways, the accumulated data strongly indicate that Faciogenital Dysplasia is a disorder of FGD1/Cdc42 signaling in the developing skeleton.

\section{EXPERIMENTAL PROCEDURES RNA In Situ Hybridization}

C57BL/6 mice were purchased from Jackson Laboratory and bred to obtain embryos and pups. Embryos were removed at various ages and staged according to Kaufman (1992); noon of the day of detection of a vaginal plug was considered embryonic day (E) 0.5. All animal experiments were carried out under the approval of the University of Michigan Committee on Use and Care of Animals. Tissues and embryos were positioned in OCT compound (Sakura, CA), rapidly frozen in hexane with dry ice, and $10-12-\mu \mathrm{m}$ serial sections 
were made using a Zeiss HM500 cryostat. Sections were treated for hybridization as described (Simmons et al., 1989) with modification. Sections were fixed in $4 \%$ paraformaldehyde-PBS for $1 \mathrm{hr}$ at room temperature, incubated in $100 \mathrm{mM}$ Tris-HCl ( $\mathrm{pH} 8.0), 50 \mathrm{mM}$ EDTA, $1 \mu \mathrm{g} / \mathrm{ml}$ of proteinase $\mathrm{K}$ for $15 \mathrm{~min}$ at $37^{\circ} \mathrm{C}$, and incubated in $100 \mathrm{mM}$ triethanolamine, $\mathrm{pH} \mathrm{8.0,0.25 \%}$ $(\mathrm{v} / \mathrm{v})$ acetic anhydride for $10 \mathrm{~min}$ at room temperature. Following acetylation, sections were washed twice in $2 \times \mathrm{SSC}$, and dehydrated in graded alcohols. The 503-bp Pst I/EcoRI fragment (nt 2577-3080) from the 3' untranslated region of the mouse $F g d 1$ gene (Pasteris et al., 1995) was used as template to generate $\left[{ }^{35} \mathrm{~S}\right] \mathrm{UTP}-$ labeled sense and antisense riboprobes to a specific activity of approximately $3 \times 10^{9}$ disints $\mathrm{min}^{-1}$ $\mu \mathrm{g}^{-1}$ RNA per the recommendations of the RNA polymerase supplier (Novagen, WI). In situ hybridization was performed as described (Keegan et al., 1994) with modifications. Sections were hybridized in 50\% formamide, $0.6 \mathrm{M} \mathrm{NaCl}, 10 \mathrm{mM}$ Tris-HCl (pH 7.5), $1 \mathrm{mM}$ EDTA, $50 \mu \mathrm{g} / \mathrm{ml}$ heparin, $10 \mathrm{mM}$ DTT, 10\% PEG-8000, $1 \times$ Denhardt's solution, $0.5 \mu \mathrm{g} / \mathrm{ml}$ tRNA at a final concentration of approximately $9 \times 10^{4}$ disints $\mathrm{min}^{-1}$ $\mu \mathrm{l}^{-1}$ in a humid chamber for $16-24 \mathrm{hr}$ at $58^{\circ} \mathrm{C}$. Following post-hybridization washes, slides were coated with NBT2 emulsion (diluted 1:1 with $0.3 \mathrm{M}$ sodium acetate) and exposed at $4^{\circ} \mathrm{C}$ for 5-14 days; exposure times were guided by overnight exposures to Hyperfilm-MP (Amersham, IL). Slides were developed in D19 developer per supplier recommendations (Kodak, NY), and counter stained with cresyl violet. Slides were viewed with a Leitz Orthoplan microscope; images were digitally captured using a Sony DKC5000 CCD camera and were directly imported into Adobe PhotoShop 5.0.

\section{Antibodies}

Polyclonal anti-Fgd1 antibodies were produced by immunizing New Zealand white rabbits with a multiple antigen peptide (MAP) containing the synthetic peptide GFEVGPPEAGERPDRRHVFKIT (Fgd1 residues 871-892) covalently linked to a polylysine core peptide. Immune sera and polyclonal antibodies were prepared by standard procedures (Harlow and Lane, 1999). Polyclonal antibodies were selected based on the immunoreactivity of the immune sera in Western blots studies using Fgd1 expression constructs in control and transiently transfected cell lines and immunohistochemical staining analyses. Dr. R. Franceschi (University of Michigan) generously provided the rabbit anti-bone sialoprotein (BSP) antibody.

\section{Histochemical Staining and Immunocytochemistry}

Frozen tissue sections were fixed in $4 \%$ formalin-PBS for $30 \mathrm{~min}$. Hematoxylin and eosin staining was performed as described (Bancroft and Stevens, 1996). Von Kossa staining was performed to identify mineralized bone tissue as previously described (Long et al., 1990). Alizarin S red staining was performed to identify cal- cified tissues as described (Bancroft and Stevens, 1996); following alizarin staining, sections were counterstained with methyl green as previously described (Harlow and Lane, 1999). For immunohistochemical staining, frozen tissue sections and cultured primary mouse calvarial cells on coverslips were fixed in $10 \%$ formalin for $30 \mathrm{~min}$, rinsed in water, and incubated in $0.02 \%$ hydrogen peroxide for $30 \mathrm{~min}$. Immunohistochemical staining was performed with the ImmunoPure $\mathrm{ABC}$ peroxidase rabbit IgG staining reagents per the producer's recommendations (Pierce, IL) with modifications. Slides were rinsed in PBS, $0.1 \%$ Tween 20 for $20 \mathrm{~min}$ and incubated in blocking solution $(1.5 \%$ goat serum, $20 \mathrm{mM}$ Tris- $\mathrm{HCl}, \mathrm{pH} 7.4,150 \mathrm{mM} \mathrm{NaCl}$, $0.01 \%$ Tween $20,5 \%$ milk) for $1 \mathrm{hr}$. Slides were incubated in antibodies (1:100 anti-BSP or 1:50 anti-Fgd1) in blocking solution overnight at $4^{\circ} \mathrm{C}$. Bound antibody complexes were detected using the $\mathrm{DAB} /$ metal concentrate substrate per producer's recommendations (Pierce, IL). Slides were dehydrated with a series of alcohol washes, dried, and coverslips were mounted with Permount (Fisher).

\section{Cell Lines and Primary Mouse Cells}

The non-transformed osteoblast-like mouse cell line MC3T3-E1 (Sudo et al., 1983) was obtained from Dr. Franceschi. Cell lines derived from human osteosarcomas, MG-63 (Franceschi et al., 1985) and SaOS (Rodan et al., 1987), were obtained from Dr. Long (University of Michigan). Mouse embryonic fibroblast cell lines C3H10T1/2 (clone 8) and NIH-3T3, transformed human embryonic kidney cell line HEK 293, and SV40 transformed green monkey cell line COS1 were obtained from the American Type Culture Collection (Rockville, MD). MC3T3-E1 cells were cultured in $\alpha$-modified minimum essential medium ( $\alpha$-MEM) and MG-63 cells were cultured in RPMI 1640 medium; all other cell lines were cultured in Dulbecco's modified Eagle Medium (DMEM). All media was supplemented with $10 \%$ fetal calf serum (FCS). Primary mouse calvarial cells were isolated as previously reported (McCauley et al., 1996) with modifications. Calvaria of 1-4-day-old mice were dissected, isolated from periosteum, and subjected to sequential digestions of 20,40 , 90 , and $60 \mathrm{~min}$ in $2 \mathrm{mg} / \mathrm{ml}$ collagenase A (BoehringerMannheim, IN) with $0.25 \%$ trypsin (Gibco BRL). Cells from the third and fourth digest were washed, counted, and plated in $\alpha$-MEM supplemented with $10 \%$ FCS, 50 $\mu \mathrm{g} / \mathrm{ml}$ ascorbic acid and $10 \mathrm{mM} \mathrm{Na} \beta$-glycerol phosphate at a density of 55,000 cells $/ \mathrm{cm}^{2}$. Primary cultures were used without passage. Cultures were incubated in a humidified incubator in $5 \% \mathrm{CO}_{2}$ at $37^{\circ} \mathrm{C}$.

\section{Expression Constructs and Cell Transfections}

The pTARGET vector (Promega, WI) was modified to generate an expression vector containing a translation initiation consensus sequence and myc-epitope tag. To generate vector pTE, pTARGET DNA was digested with EcoRI and ligated to annealed oligomers: 5'AAT- 
TGCAGCCACCATGGAGCAGAAGCTGATCTCCGAGGAGGACCTG-3' and 5'AATTCAGGTCCTCCTCGGAGATCAGCTTCTGCTCCATGGTGGCTGC-3'. To generate vector pTGE, pTE DNA was digested with EcoRI and ligated to annealed oligomers: 5'AATTTAGGATCCCGGGCTAGCCATATGCTCGAGACGCGTCGACG-3' and 5'-AATTCGTCGACGCGTCTCGAGCATATGGCTAGCCCGGGATCCTA-3'. The pTGE-myc-Fgd1 expression construct was generated by cloning the $\mathrm{Fgd1} \mathrm{BlpI} /$ EcoRI cDNA restriction fragment (residues 18-960; Pasteris et al., 1995) into pTGE in frame. All constructs were verified by DNA sequencing. COS1 and HEK 293 cells were transiently transfected using LipofectAMINE Plus reagent per the manufacture's protocol (Gibco BRL, MD). Cells were harvested 48-72 hr after transfection.

\section{Immunoblotting}

Cells and postnatal mouse tissues were homogenized in ice-cold extracting buffer containing $25 \mathrm{mM}$ Tris$\mathrm{HCl}(\mathrm{pH} 7.4), 250 \mathrm{mM}$ sucrose, $5 \mathrm{mM}$ EDTA, $2 \mathrm{mM}$ phenylmethylsulfonyl fluoride (PMSF) in the presence of a $1 \%$ protease inhibitor cocktail [4-(2-aminoethyl)benzenesulfonyl fluoride, pepstatin A, transepoxysuccinyl-L-leucylamido(4-guanidino)butane, bestatin, leupeptin, and aprotinin] (Sigma, St. Louis, MO). Following a Bradford protein assay (BioRad Laboratories) using $\mathrm{BSA}$ as standard, protein homogenates were diluted in Laemmli sample buffer, separated by SDS-PAGE (Laemmli 1970) and electrotransferred onto Immobilon-P membranes (Millipore, MA) (Towbin et al., 1979). Membranes were incubated in anti-Fgd1 antibody $(1: 5,000)$ or monoclonal anti-myc epitope antibody (1:10,000; Invitrogen) overnight at $4^{\circ} \mathrm{C}$. Immunoblots were incubated with secondary HRP-conjugated antibody (1:10,000; Pierce), and detected using chemiluminescent reagents (ECL; Amersham).

\section{Clinical Evaluation of Faciogenital Dysplasia Patients}

Informed consent was obtained from all participants evaluated at the University of Michigan Medical System in accordance with the Human Subjects Research Committee. Clinical evaluations were obtained without prior knowledge of genotype status. Physical examination and radiographic studies were used to assess skeletal abnormalities. Several extensive patient clinical evaluations have been reported previously (Gorlin et al., 1990; Porteous and Goudie, 1991); detailed skeletal findings of the other patients are our unpublished data.

\section{ACKNOWLEDGMENTS}

This work was supported in part by National Institutes of Health grant 5T32HD07505-02 to L.E. and grant HD34446 to J.L.G. We thank B. W. Donohoe, C. A. Edwards, L. McCauley, and A. F. Seasholtz for technical advice and assistance, R. Franceschi for antibodies, and R. Franceschi, and M. Long for cell lines.

\section{REFERENCES}

Bancroft JD, Stevens A. 1996. Theory and practice of histological techniques, 4th ed. New York: Churchill Livingstone.

Bianco P, Fisher LW, Young MF, Termine JD, Robey PG. 1991. Expression of bone sialoprotein (BSP) in developing human tissues. Calcif Tissue Int 49:421-426.

Boguski MS, McCormick F. 1993. Proteins regulating Ras and its relatives. Nature 366:643-653.

Cerione RA, Zheng Y. 1996. The Dbl family of oncogenes. Curr Opin Cell Biol 8:216-222.

Eriebacher A, Filvaroff EH, Gitelman SE, Derynck R. 1995. Toward a molecular understanding of skeletal development. Cell 80:371-378.

Franceschi RT, James WM, Zerlauth G. 1985. 1,25-dihydroxy $\mathrm{D}_{3^{-}}$ specific regulation of growth, morphology and fibronectin in a human osteosarcoma cell line. J Cell Physiol 123:401-409.

Gorlin RJ, Cohen MM, Levin LS. 1990. Syndromes of the head and neck, 3rd ed. New York: Oxford University Press.

Gorski JL. 1998. Aarskog-Scott syndrome. In: Jameson L, editor. Principles of molecular medicine. Totowa: The Humana Press Inc. p 1039-1045.

Hall A. 1998. Rho GTPases and the actin cytoskeleton. Science 279: 509-514.

Harlow E, Lane D. 1999. Using antibodies: a laboratory manual. Cold Spring Harbor, NY: Cold Spring Harbor Laboratory Press.

Kaufman MH. 1992. The atlas of mouse development. London: Academic Press.

Keegan CE, Herman JP, Karolyi IJ, O'Shea KS, Camper SA, Seasholtz AF. 1994. Differential expression of corticotropin-releasing hormone in developing mouse embryos and adult brain. Endocrinology 134:2547-2555.

King JA, Marker PC, Seung KJ, Kingsley DM. 1994. BMP5 and the molecular, skeletal, and soft-tissue alterations in short ear mice. Dev Biol 166:112-22.

Laemmli UK. 1970. Cleavage of structural proteins during assembly of the head of bacteriophage T4. Nature 227:680-685.

Long MW, Williams JL, Mann KG. 1990. Expression of bone-related proteins in the human hematopoietic microenvironment. J Clin Invest 86:1387-1395.

Olson MF, Pasteris NG, Gorski JL, Hall A, 1996. Faciogenital Dysplasia Protein (FGD1) and Vav, two related proteins required for normal embryonic development are upstream regulators of Rho GTPases. Curr Biol 6:1628-1633.

Majeska RJ. 1996. Culture of osteoblastic cells. In: Bilezikian JP, Raisz LG, Rodan GA, editors. Principles of bone biology. San Diego: Academic Press. p 1229-1237.

McCauley LK, Koh AJ, Beecher CA, Cui Y, Rosol TJ, Franceschi RT. 1996. PTH/PTHrP receptor is temporally regulated during osteoblast differentiation and is associated with collagen synthesis. J Cell Biochem 61:638-647.

Pasteris NG, Cadle A, Logie LJ, Porteous MEM, Schwartz CE, Stevenson RE, Glover TW, Wilroy RS, Gorski JL. 1994. Isolation and characterization of the faciogenital dysplasia (Aarskog-Scott syndrome) gene: a putative rho/rac guanine nucleotide exchange factor. Cell 79:669-678.

Pasteris NG, de Gouyon B, Cadle AB, Campbell K, Herman GE, Gorski JL. 1995. Cloning and regional localization of the mouse faciogenital dysplasia (Fgd1) gene. Mamm Genome 6:658-661.

Pavalko FM, Chen NX, Turner CH, Burr DB, Atkinson S, Hsieh Y-F, Qui J, Duncan RL. 1998. Fluid shear-induced mechanical signaling in MC3T3-E1 osteoblasts requires cytoskeletal-integrin interactions. Am J Physiol 275:C1591-C1601.

Porteous MEM, Goudie DR. 1991. Aarskog syndrome. J Med Genet 28:44-47.

Robey PG 1996. Bone matrix proteoglycans and glycoproteins. In: Bilezikian JP, Raisz LG, Rodan GA, editors. Principles of bone biology. San Diego: Academic Press. p 155-165.

Rodan GA, Imai Y, Thiede MA, Wesolowski G, Thomson D, BarShavit Z, Shull S, Mann K, Rodan GA. 1987. Characterization of a 
human osteosarcoma cell line (SaOS-2) with osteoblastic properties. Cancer Res 47:4961-4966.

Simmons DM, Arriza JL, Swanson LW. 1989. A complete protocol for in situ hybridization of messenger RNAs in brain and other tissues with radiolabeled single-stranded RNA probes. J Histotechnology 12:169-181.

Storm EE, Huynh TV, Copeland NG, Jenkins NA, Kinsley DM, Lee S-J. 1994. Limb alterations in brachypodism mice due to mutations in a new member of the TGF beta-superfamily. Nature 368:639-43.

Sudo H, Kodama H, Amagai Y, Yamamoto S, Kasai S. 1983. In vitro differentiation and calcification in a new clonal osteogenic cell line derived from newborn mouse calvaria. J Cell Biol 96:191-198.

Tanaka-Kamioka K, Kamioka H, Ris H, Lim S-S. 1998. Osteocyte shape is dependent on actin filaments and osteocyte processes are unique actin-rich projections. J Bone Miner Res 13:1555-1568.
Toma CD, Ashkar S, Gray ML, Schaffer JL, Gerstenfeld LC 1997. Signal transduction of mechanical stimuli is dependent on microfilament integrity: identification of osteopontin as a mechanically induced gene in osteoblasts. J Bone Miner Res 12:1626-1636.

Towbin H, Staehelin T, Gordon J. 1979. Electrophoretic transfer of proteins from polyacrylamide gels to nitrocellulose sheets: procedure and some applications. Proc Natl Acad Sci USA 76:4350-4354.

Van Aelst L, D'Souza-Schorey C. 1997. Rho GTPases and signaling networks. Genes Dev 11:2295-2322.

Whitehead IP, Campbell S, Rossman KL, Der CJ. 1997. Dbl family proteins. Biochim Biophys Acta 1332:F1-F23.

Zheng Y, Fischer DJ, Tigyi G, Pasteris NG, Gorski JL, Xu Y. 1996 The faciogenital dysplasia gene product $F G D 1$ functions as a Cdc42Hs-specific guanine-nucleotide exchange factor. J Biol Chem 271:33169-33172. 